\title{
Die ou digter en die jong hond
}

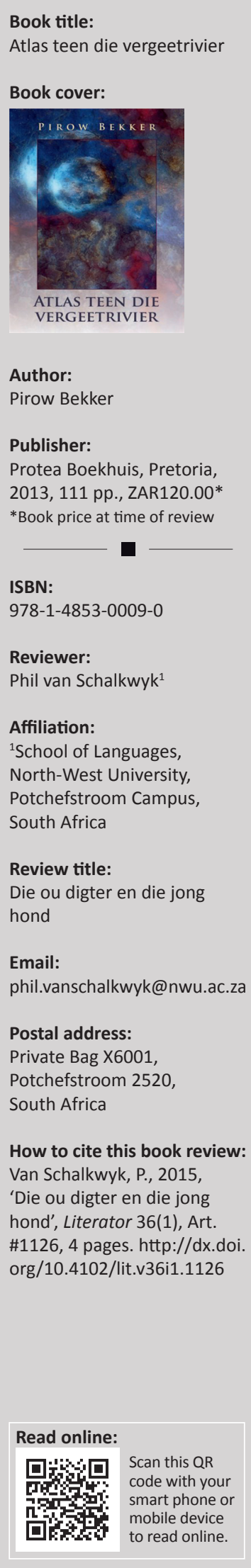

Pirow Bekker (1935-) was al in verskeie professionele hoedanighede werksaam - verslaggewer, dosent, navorser, boeksamesteller, boer - en het as skrywer oor meer as vier dekades heen met betreklike sukses werk in verskeie genres gelewer, vanaf romans tot radiodramas. Sy sterkste bydrae is egter ten opsigte van die kortverhaal, waarmee hy Hennie Aucamp, voorste Afrikaanse kortverhaalkenner en -beoefenaar, al teen 1985 van sy meesterskap oortuig het (vgl. Aucamp 1987), en die poësie, wat algaande tot die sterkste en mees standhoudende aar van sy skrywerskap ontwikkel het.

Afrikaanse poësieliefhebbers en Bekker-lesers moes vyf jaar wag vir 'n nuwe bundel van hierdie veteraan van die Afrikaanse letterkunde. Atlas teen die vergeetrivier (2013) bevat'n stewige aanbod, sowel kwantitatief as kwalitatief gesproke. Daar is wel nog iets van die ongelykheid wat kritici al in die werk van Bekker uitgewys het. Oor die betekenis en kwaliteit van sommige gedigte, bv. 'Inhoudsmaat', 'Daar is monsters', 'Die pad is 'n pad is' en 'The sky is not the limit', het ek selfs na talle herlesings bly twyfel.

Bekker se poësie toon die afgelope dekade in terme van gehalte nietemin 'n stygende lyn met werk wat opvallend in die rigting van die ouderdomspoësie neig, naamlik die bundels Stillerlewe (2002) en Van roes en amarant (2008). Hierdie tendens word met Atlas teen die vergeetrivier voortgesit. Trouens, ouderdomspoësie is een van die sterkste groeipunte van die Afrikaanse poësie die afgelope jare.

In Atlas teen die vergeetrivier benut Bekker verskillende betekenisassosiasies van A/atlas: in die eerste instansie, uit die mitologie die Titaan, Atlas, wat die aarde (eintlik meer korrek: die hemelse sfere) op sy skouers dra, maar onder meer ook die atlas as bundel aardrykskundige kaarte en, anatomies, die draerwerwel, vernoem na Atlas van ouds, wat dit moontlik maak om die kop te draai, en waarmee dan ook weer 'n verband met die aardbol opgeroep word.

Die opvallende van Bekker se ouderdomspoësie in Atlas teen die vergeetrivier is dat die eksistensiële krisis en aftakeling van oud word nie as onoorkombaar voorgestel word nie en dat die ouderdomsbelewing nie in 'n gelate mineurtoon verwoord word nie. Alhoewel daar merendeels nie soos by Dylan Thomas van 'Rage, rage against the dying of the light' (vgl. (DeRoche 1996:441-442) sprake is nie, word teenslae, dood en die Groot Vergeet van Lete met 'n onverskrokke, optimistiese gesindheid gekonfronteer, soos dit in 'Skeepsbeleg' verwoord word: 'daar [is] net een pad oor: te wys/ kaduks skrik jy jou nie'. Die gedig 'Om oud te gaan' bied weliswaar 'n somber perspektief daarop om 'oud heen te gaan' en bevestig met verwysing na die digters Jacques Perk, Ingrid Jonker en John Keats die bekende uitspraak 'The good die young'. Wat egter opval, is die vitaliteit van die versgang en stelwyse, al word dan ook ten slotte besin oor Willem Kloos wat, byna tragies, nog dekades ná die 'afloop' van die Tagtiger-'beweging' getrou gebly het aan sy digterlike manifes, soos verwoord in die derde strofe:

\footnotetext{
Wat ook al verder sou gebeur,

hulle is ten minste die sonde gespaar

van beloftes wat onvervuld bly

soos die arme Willem Kloos

wat die golf van emosie kon ry, en toe

is daar geen golf meer nie,

net' $n$ halwe eeu se lae gety.
}

In 'Die groot moeg' word aangevoer dat elke vorm van bewaring, (self)behoud en herdenking, ook die 'Gravering in graniet/ met geboorte-/ en uitvaartdag', wel 'n doel dien:

Dit hou die stryd

teen die totnietmaker vol,

dit laat dalk die donder sien 
sy angel is ' $n$ spaan

na die anderkant.

Die totnietmaker 'verdien die uitklophou, die mat', en hiermee word die bekende boks-, stoei- en kragmanmotief in Bekker se oeuvre, waarvan sy roman Manna kommering (1980) die hoeksteen is, weer opgeroep, en herhaal in gedigte soos 'Klimmers' en 'Liggaamsbouer keer in'. Die oorwinnings- en veroweringsdrang word in die slotgedig bevestig waar daar gesê word: "n hele vasteland lê voor my braak,/ en ander waar die oog kan reik,/ seë om oor te steek, te toer'.

Bekker stel in hierdie bundel die sterflike en die ouderdom in verhouding tot alles wat van hoë waarde is, hetsy die natuurlike of die mensgemaakte, wat hy van die vergetelheid probeer 'red'. Soos in sy vorige bundel, gaan dit ook hier, maar dan in verhewigde formaat, om die verhouding tussen die verganklike ('roes') en die onverwelklike ('amarant').

Met direkte intertekstuele verwysing na N.P. van Wyk Louw se 'Ballade van die nagtelike ure' word in 'Oor die uur van die donker dors' ingegaan op die 'erkenning van die drang/ na meer as middernag se wip', en besin oor die brug wat 'skemer deur ontgogeling .../ na meer beleë sensasies as wat lei/ na bitters oor 'n glas se rand gemors'. Daar word gedors na 'n danser wat ook 'bruggimnas' is: 'Wees op jou pos gevaarlik hoog/ sodat vir my wat hangend, hangend is / jy op die regte tyd om vas te gryp/ die sweefstok, in jou hand, laat val'. Hierdie reddende raakvang tydens die salto mortale, hierdie wedersyds aanvullende verhouding van lewe en dood word in die kort gedig 'Interval' met implisiete verwysing na Van Wyk Louw se sonnet 'Nog in my laaste woorde' (vgl. Brink 2008:131) nogeens onder woorde gebring: 'Mooi is die lewe en die dood is / Asembenemende/ reënboogvis'.

In 'Nie om die hond nie', wat saam met die gedig 'Nota bene: ons retriever' gelees kan word, word die verhouding met die sterflike, in aansluiting by die positiewe voorstelling van die jeugdige en die kinderlike in Bekker se oeuvre, uitgebeeld met verwysing na 'n lewenskragtige, spelende, jong hond (wat toegeëien word as 'my hond'). Hierdie jong hond kan gesien word as voorstellend van die 'jeugdige' kop op die spreker se bejaarde lyf, soos onder meer gesuggereer deur die versreël, 'Kom, gee kop, my honne', en skakel met die draerwerwelmotief in die bundel. Daarom gaan dit inderdaad hier nie om die hond nie soos die titel van hierdie gedig dit stel! Die kop staan hier moontlik in verband met 'droomend denken', om die bekende poëtikale bewoording van die Simbolis J.H. Leopold in sy gedig 'De molen' (vgl. Cloete 1977:13-15) by te haal. Die digter-spreker se hond/kop beur vooruit en storm in strofe drie agter ' $n$ meeu aan die see in, 'oor golwe soos 'n hoogspringperd', en retrieve inderdaad iets, iets met Simbolistiese allure: 'kom pas gebore terug en skud/ 'n wolk druppels oor my hare los'. Die digterlike denke maak dus self reën. 'Nie om die hond nie', spesifiek die voorstelling van die kop, skakel met 'Verby die aarde se toedoen' waarin die aardbol voorgestel word as nog lank nie 'opgebruik' nie, dus nog jonk, en sy 'buie reën ... kom lê/ op jou wimpers, bo die taai van die vergete trane', soos die 'hemelse' druppels wat bo-oor die kop uitgeskud word deur die hond as metafisiese retriever.

Een van die mees verfrissende aspekte van Atlas teen die vergeetrivier is dat daar meer as 'n sweempie jeugdige voortvarendheid in Bekker se digkuns te bespeur bly. In die slotgedig, 'Vlugbrug', word die besef van die beperkinge en onsekerhede van die ouderdom se tydreis versoen met die onoorwinlike deur te sluit met verwysing na die manjifieke (kop van) Absalom: 'Maar ek,/ aan twintig eeue haardos vasgepen,/ my oë bly absalom gesper'. Daar word dan ook op die vlak van tematiek en motiewe besin oor voortvaar, -marsjeer, -rank en ten opsigte van die poëties stilistiese word daar, by wyse van spreke, uit volle bors voor(t)gesing. Een van die treffendste gedigte in hierdie verband, én in die bundel as geheel, is die 'sterk' bewoorde 'Ou seevaarder steek boeg', wat ek volledig aanhaal:

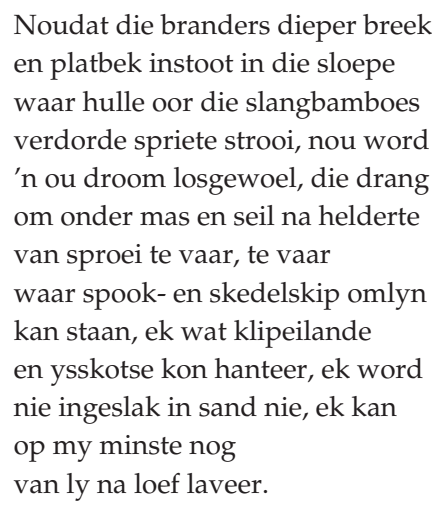

Hierdie gedig as geheel, maar veral die kragtige slotreël, bevestig Bekker se woordvaardigheid. 'Ly' en 'loef' is onderskeidelik die kant van die skip wat weg van en na die wind gekeer is, en 'laveer' verwys na die gepaste manier waarop 'n teëwind die hoof gebied word, naamlik deur sigsag te vaar. Hierdie gedig onderstreep die vasberade ingesteldheid wat die bundel onderlê, sowel ten opsigte van die bestaansproblematiek as die poëtiese.

Die druppels wat aan die einde van die reeds vermelde 'Nie om die hond nie' byna soos 'n buitjie reën oor die spreker uitgeskud word, skakel met die 'vegetasie'- en plantemotief wat redelik prominent in die bundel na vore kom, naamlik onder andere in: 'Om 'n brug te slaan'; 'Golfsekuriteitsoord'; 'Paradys'; 'Ingewing'; 'Waarin die liefde lê'; 'Bottelblom'; 'Meer boom'; 'Randfiguur'; 'Kopatlas'; 'Oogopslag'. In 'Ruigtesanger' word herlewing, die kringloop van die lewe, opgeroep. Daar word gesing van 'klei en struikgewas// wat vervleg is met jou drome'; die lied wat 'die oerwoud in' gesing word, 'word elke more// soos uit vallende water/ wat nie weet waarheen nie/ maar moet val, opnuut gebore'. In 'Natuurkrag' word gespog met die eie tuin: die 'noemnoem', 'kei-appels', ensovoorts, wat geil groei. 'Maar dis die dorings waarop ek eintlik let', meld die spreker. Die 'een loot bind sy naaste in', en so word muishond en kobra gefnuik. 'My liewe dood, ek noem dit net', só lui die slotreël van hierdie gedig. 
Trouens, van die gedigte wat die sterkste en blywendste indruk op my gemaak het, hoort tot hierdie 'vegetasie'kategorie. Hier verwys ek spesifiek na die eenvoudige, netjies afgeronde kwatrynegediggie 'Ek plant vir jou', waarin 'n malva vir die geliefde in 'n pot geplant word, gereed 'om hoog te hang in jou balkon/ waar die grysbokkie nie kan kom/ om snags die blomme af te vreet'. Die hoogtepunt van hierdie groep gedigte en moontlik van die bundel as geheel, is myns insiens die gedig 'Klimmers': dit is 'n besonder raak studie van rankplante waarin die wonder van raakrank heel gepas verwoord word in trefseker taal en met sekure verstegniek. Met sy spesifiek Suid-Afrikaanse verwysingsveld en die benutting van die stoeikrytmotief word daarin geslaag om iets betekenisvols oor ons land en oorlewing hier, sowel by natuur as mens, verwoord te kry. Vergelyk die tweede strofe:

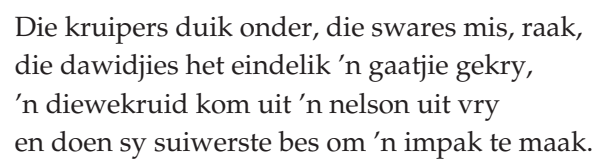

Bekker beoefen in Atlas teen die vergeetrivier ook 'n meer uitgesponne poësie wat, soos gesien, herinner aan die Simbolistiese werk van die Nederlandse Negentigers (1890's), spesifiek die komplekse langer gedigte van Leopold. Soos die windmeul in Leopold se 'De molen' vanuit die nog in skadu gehulde, roetbesmeerde stad verrys, met die wieke in die lig, en daardeur poëtikaal metafoor word van die Simbolisme, so staan die brug in 'Om 'n brug te slaan', 'geaard', 'soos die eerste bome/ wat wolkekrabbers geword het', en nadat hulle gekantel het tot brug, soms weer 'treusel in 'n loot/ en nuut uit die wortel uit/ na 'n hemel reik'. In 'Mol in die son' kom die onderaardse gediertetjie vanuit die donkerte bogronds te voorskyn met 'babapienk' pote en 'ruimtepakblink' pels, 'soos in 'n weergeboorte/ glad weggekam', agter die 'warm knol daar bo' aan, om dit 'blindweg te omhels'. Die 'Simbolistiese' projek verloop egter nie vlot nie: In 'Meer boom' word gewys op die weerstand en die onvolmaaktheid, veral dan ook vir sover dit die pogings van die kunstenaar aangaan. 'Die pad na volkomenheid' word in die slot van hierdie gedig spesifiek op die artistieke betrek: 'Teen so 'n militante kompleks/ is daglighelderheid ontoereikend,/ moet nog aan gewerk word/ soos aan 'n hemelhoë boom/ se rietskrale koolstofskets'. Die slotformulering, in die laaste twee reëls, bind ook die werklike, 'aardse' boom en die meer 'verhewe', getekende boom vernuftig saam.

Atlas teen die vergeetrivier is ' $n$ bundel van groter as lewensgroot mitiese gebare: diep geaarde (metaforiese) brûe word oor wydtes gespan, en ons tref die primordiale Atlas aan 'wat sy bevoelde aarde op sy skouer lig/ en oor sy hangbrug dra', soos dit al aangekondig word in die losstaande opdraggedig 'Toekomende verlede', en verder ontwikkel word in ses afdelings met opskrifte waarin reeds ' $n$ bepaalde dinamika en progressie af te lees is: 'Die aard van brûe', 'Verbrande hebbelikhede' (wat ook iets van verbrande brûe suggereer), 'Lyfdrif', 'Die wêreld het nog te veel oor vir jou', 'Ruigtelied' en 'Vlugbrug'.
Met hierdie bundel, die negende, begin die idiolektiese en standhoudende van Bekker se digterskap al duideliker na vore kom. Louise Viljoen het in 2008 in Die Burger in haar resensie van Van roes en amarant aangevoer dat daardie bundel, soos die vorige twee, tref 'omdat dit die tekstuur het van iets soos grond en grint'. Daar sou myns insiens beweer kon word dat Pirow Bekker in sekere opsigte Afrikaans se Seamus Heaney is. Die aardse verwysingsveld, waaraan dan ook 'n robuuste tongval en uitsterwende dog geharde woordeskat gekoppel word, deel Bekker met die groot Ierse digter. Dink maar aan Heaney se 'Digging' (Heaney 1990:1-2), 'n gedig oor die digter-spreker se vader en die eie skrywerskap, en ook 'n prototipiese Heaney-gedig, waarvan die tweede laaste strofe lui:

The cold smell of potato mould, the squelch and slap

Of soggy peat, the curt cuts of an edge

Through living roots awaken in my head.

But I've no spade to follow men like them. (Heaney 1990:2)

Tematies sluit hierdie gedig aan by Bekker se 'Kopatlas', 'n ontroerende gedig oor vader en seun in Atlas teen die vergeetrivier, asook by 'n vroeëre gedig van Bekker, 'Sonnet by oupa se portret' uit die 1975-bundel Toekomstige betrekkinge. Waar die verhouding tussen die handvaardige vader en die skrywerseun in Heaney se gedig beeldend voorgestel word met die kontrasterende en uiteindelik versoende 'spade' en 'pen', word 'n soortgelyke verhouding tussen oupa en seun by Bekker in 'Sonnet by oupa se portret' verwoord deur 'n spel met 'son' en 'sonnet' (Bekker 1975:32). Waar die (klein) seun in hierdie gedigte van Bekker en Heaney opkyk na die groot voorvader, vind daar in 'Kopatlas' 'n ommekeer plaas, deurdat die pa, tot boomhuisbou onbekwaam (die 'platkruin langs die oprit' leen hom ook nie daartoe nie), onwillekeurig uitsien 'na die koms van die seun', 'die ware Jakob'. Dis 'n hoopvolle 'immerpa' wat 'oor sy vinger [bly] voorlees' met iets van: 'Waar was ons nog laas gewees?' 'Immerpa' mag hier verskillende betekenisassosiasies hê: die pa wat altyd pa bly, getrou aan sy taak as vader; die ewige of universele pa; deur die moontlike assosiasie met 'immergroen' die pa wat altyd beskermend daar is, 'met sy platkruin ongeskonde'; maar dan ook, miskien, die pa wat altyd, juis ook in sy vadersrol, 'groen' (onbeholpe, nat agter die ore, jeugdig) sal bly; of die pa met die immergroen kop (verstand) wat hom enersyds bemagtig, maar andersyds ook krities en bewus van sy eie beperkinge hou.

Bekker is bekend vir die omvang en gevarieerdheid van sy taalrepertorium, wat insluit die benutting van die spreek- en streektaal, en ook in hierdie verband toon hy in Atlas teen die vergeetrivier, veral in die plantegedigte, verwantskap met Heaney (1990:127) se konserverende en trefseker aanwending van die 'mud-flowers of dialect' ('Song'). Maar 'dialek' het vir my met betrekking tot Bekker ook 'n ander assosiasie, naamlik dat hy nog 'n Afrikaans beheers en beoefen wat met sy komplekse sinsbou, omvattende leksikon en (ontykende) aanwending van ons idiomatiese erfenis vir heelwat Afrikaanssprekendes van vandag iets van 'n dialektiese vreemdheid moet besit. Bekker se digkuns vertoon 'n sterk historiese bewussyn, en dít word ook in sy 
taalkeuses gereflekteer. Hy skryf in sy beste gedigte met al die registers van Afrikaans wyd oop. Voeg daarby die verwikkelde retoriese 'lyne' en verstegniek, en die leser kan gou die spoor byster raak.

Bekker is self terdeë bewus van die toenemende veryling van Afrikaans. In die satiriese afdeling 'Verbrande hebbelikhede', waarin hy hekelgedigte wy aan alles vanaf die eiendomsmark-mantra 'ligging, ligging, nogmaals ligging' tot glanspersoonlikhede en golfsekuriteitsoorde, staan twee besonder onthoubare gedigte oor Afrikaanse taalverarming. In 'Woordskroot' word die verlies aan selfs meer gewone woorde soos 'albei' en 'sowel as', en die verdringing van 'hiermee' deur 'met dit' en ander dergelike gevalle betreur. Kostelik is hoe daar in die slotgedeelte van die gedig in die nuwe karige, eentonige idioom gepraat begin word, maar dan met die skrynend waar insig dat dit uiteindelik ook gaan oor ontmensliking: 'Met dié dat jy nie kan uitmis nie op dit/ en dit onmoontlik lyk om dit te beat/ geen show meer vry is nie van dit,/ het jy jou aangesluit by die falanks / wat mense ontruim, nie 'n huis of 'n stad'. 'n Soortgelyke betoog word in 'Woordweë' gelewer. Hier word gefokus op die sanering van Afrikaans, in die uitsaaiwese, ten opsigte van woorde wat voorheen spesifiek vir diere gebruik is. Veral 'argaïestiese Afrikaanse woorde/ soos "pens" en "pote" moet nou uit die woordeskat geweer word, ten gunste van 'maag' en 'voete'. In dertien kwatryne word op gevatte wyse op talle ander sulke voorbeelde ingegaan. Vergelyk strofes sewe en nege:

Geen diere raak meer 'speuls' nie, ook nie 'ritsig';

'loops' en 'jags' is in ons uitsaaiwerk taboe,

'brons' en 'bronstig' is miskien nog gangbaar,

maar sê liewer dat hul 'paargereed' of 'op hitte' is.
Kom dit by geboorte is ons dikwels nie diskreet nie. Wat vir ons mense geld, kan net sowel vir diere dien: Waarom moet ' $n$ vark juis jong, 'n merrie vul? $\mathrm{Al}$ wat nog deesdae kalf, is 'n masjien.

Ook hier gaan dit uiteindelik oor verlies aan (mede) menslikheid, soos gestel in die slotstrofe:

Voorbeelde van die wêreldwye ommekaar is oral uitgespel maar 'n skoonheidskundige Elizabeth Arden het dit stileer toe ' $n$ afrigter ongans omgaan met die vog uit huid en vel hy so in die bek geruk is: Mense sweet; my perde perspireer.

Atlas teen die vergeetrivier is 'n ryk en geskakeerde bundel waarop enige digter trots sou kon wees. Dis nie net 'n waardige toevoeging tot Bekker se oeuvre nie, maar bestendig én verruim dit wat ons by hom oor baie jare heen leer ken en waardeer het. Waarlik inspirerend is dit om 'n nuwe bundel van 'n digter van gevorderde leeftyd te lees waarin nie net van die beste werk in sy oeuvre gelewer word nie, maar nog met jeugdige ambisie gestreef word.

\section{Literatuurverwysings}

Aucamp, H., 1987, Dagblad, HAUM-Literêr, Pretoria.

Bekker, P., 1975, Toekomstige betrekkinge, Tafelberg, Kaapstad.

Bekker, P., 1980, Manna kommering, Tafelberg, Kaapstad.

Bekker, P., 2002, Stillerlewe, Protea Boekhuis, Pretoria.

Bekker, P., 2008, Van roes en amarant, Protea Boekhuis, Pretoria.

Brink, A. (red.), 2008, Groot verseboek: Deell, Tafelberg, Kaapstad.

Cloete, T.T. (red.), Van Leopold tot Achterberg, J.L. van Schaik, Pretoria.

DeRoche, J., 1996, The Heath introduction to poetry, D.C. Heath and Company, Lexington.

Heaney, S., 1990, New selected poems: 1966-1987, Faber and Faber, London.

Viljoen, L., 2008, 'Dié fyn spel met taal het tekstuur van grond, grint', Die Burger, 10 November, p. 11. 